Research Article

\title{
Finite-Element Analysis on Compressive Performance of a Novel Glue-Laminated Cornstalk Scrimber
}

\author{
Wei Tian (i), Yongmei Qian (D), Zunpeng Liu $(\mathbb{D}$, and Yiming Wang (iD)
}

Jilin Jianzhu University, Changchun 130118, China

Correspondence should be addressed to Yongmei Qian; qianyongmei@jlju.edu.cn

Received 26 October 2020; Revised 23 November 2020; Accepted 4 December 2020; Published 24 December 2020

Academic Editor: Gengxin Sun

Copyright (c) 2020 Wei Tian et al. This is an open access article distributed under the Creative Commons Attribution License, which permits unrestricted use, distribution, and reproduction in any medium, provided the original work is properly cited.

\begin{abstract}
Novel glue-laminated cornstalk scrimber is a new timber substitute produced by special techniques, without damaging the original fibers in cornstalks. This novel material outperforms ordinary timber in the resistance to water, damping, insect, and fire and provides a desirable green building material. However, glue-laminated cornstalk scrimber has not been widely implemented in the building industry, because the application of cornstalk products is limited to decoration panels. With the aid of the finiteelement software Abaqus, this paper simulates the glue-laminated cornstalk scrimber specimens with different slenderness ratios under axial compression and analyzes the compressive performance of such specimens. The results show that the height of gluelaminated cornstalk scrimber is negatively correlated with the buckling load and nonlinear load under axial compression and positively correlated with the transverse displacement and axial displacements induced by axial compression. The research results provide a good reference for improving the design and application of glue-laminated cornstalk scrimber.
\end{abstract}

\section{Introduction}

Konjac is a perennial herbaceous plant in the genus of Amorphophallus, Araceae family. The main active component is konjac glucomannan (KGM), a water-soluble natural polymer polysaccharide [1]. The KGM is generally considered as a polysaccharide formed by linking glucose and mannose at the ratio of $1: 1.69$ or $1.4: 1$ through $\beta-1,4$ glycosidic bonds. With a molecular weight of $200-20,000 \mathrm{kDa}$, the KGM has an acetyl group at the C6 position for every 19 sugar units on the main chain $[2,3]$.

In recent years, China has highlighted the importance of ecological civilization and further restricted timber consumption to protect forest resources. As a result, a diverse array of timber substitutes has emerged, such as scrimber and glulam $[1,2]$.

Much research has been done on timber substitutes around the world. For instance, Uzel et al. [3] compared the flexural behavior of glulam beams with that of large-volume timber beams. The University of Catania [4] described the structural behaviors of glued laminated (GL) timber and laminated veneer lumber (LVL) and introduced a new technique called post-tensioning of timber beams. Through tests and evaluation, Graz University of Technology [5] proposed a generic design approach generally applicable for all linear and planar, unidirectional, and orthogonal laminated structural timber products. The Institute for $\mathrm{Me}$ chanics of Materials and Structures [6] developed a stochastic engineering framework capable of accounting for how the random fluctuations of the stiffness of wooden boards work on the performance of glued laminated timber (GLT). Anshari and Guan [7] established a finite-element model to simulate the prestress performance of compressed wood (CW) glulam beams and further examined the structural properties of prestressed beams under destructive bending.

Cornstalks, the most common type of crop stalks, can be reconstituted and recombined into a novel timber substitute. This helps to protect the air environment and alleviate the shortage of forest resources. Therefore, the application of glue-laminated cornstalk scrimber not only boasts profound theoretical value but also has great economic and social significance [8-10]. Despite its excellent features (e.g., high density, high strength, fire resistance, corrosion resistance, 
moisture resistance, and insect resistance), glue-laminated cornstalk scrimber has only been applied as decorative panels. Few studies have attempted to implement the novel material in the building industry [11-14].

In the light of the above, this paper carries out a finiteelement simulation on the compressive performance of gluelaminated cornstalk scrimber, shedding theoretical new lights on the mechanical performance of this novel material. The research results could promote the design and application of glue-laminated cornstalk scrimber.

\section{Finite-Element Analysis on Glue-Laminated Cornstalk Scrimber under Axial Compression}

2.1. Constitutive Relationship. Glue-laminated cornstalk scrimber is a nonsymmetrical anisotropic material. To measure its compressive performance, the elastic moduli, Poisson's ratios, and shear moduli of three surfaces were recorded in the elastic phase: the fiber direction 1, the scrimber direction 2, and the bonding direction 3. Referring to the definitions of timber yield phase, the generalized Hill yield criterion [15-19] was introduced for the yield phase. Table 1 lists the performance parameters of glue-laminated cornstalk scrimber.

2.2. Finite-Element Model. The axial compression specimens of glue-laminated cornstalk scrimber were meshed into three-dimensional (3D) eight-node hexagonal elements C3D8R (Figure 1). The load was applied concentratedly on the top of the specimen. The load was fixed for the elastic model and gradually stepped up for the nonlinear model. At the bottom of the specimen, the support was allowed to rotate in one direction only; at the top, the support could rotate in one direction and displace in the axial direction. Through structural optimization, the finite-element model of glue-laminated cornstalk scrimber mainly consists of hexagonal elements $[20,21]$.

2.3. Model Size. This research only considers the overall stable bearing capacity, without tackling local stability. Therefore, the slenderness ratio of the finite-element model was changed to study its effect on the ultimate bearing capacity.

Drawing on Technical Code of Glued Laminated Timber Structures (GBT50708-2012) and Code for Design of Timber Structures (GB50005-2017), the model size was designed as follows: the sectional area was fixed at $150 \mathrm{~mm} \times 150 \mathrm{~mm}$, while the length was set to $1,200 \mathrm{~mm}, 1,600 \mathrm{~mm}, 2,000 \mathrm{~mm}$, $2,400 \mathrm{~mm}$, and $2,800 \mathrm{~mm}$, respectively. The resulting specimens were coded Z-1 to Z-5 in turn (Table 2).

\subsection{Results Analysis}

2.4.1. Eigenvalue Buckling Analysis. The eigenvalue buckling analysis aims to calculate the ultimate load that drives an elastic member from a stable state to the critical state of instability. The analysis results are consistent with the classical Euler solution. Through Abaqus calculation, the
TABLE 1: The performance parameters of glue-laminated cornstalk scrimber

\begin{tabular}{lcccccccccc}
\hline $\begin{array}{c}\text { Elastic modulus } \\
(\mathrm{MPa})\end{array}$ & \multicolumn{4}{c}{$\begin{array}{c}\text { Shear modulus } \\
(\mathrm{MPa})\end{array}$} & \multicolumn{3}{c}{$\begin{array}{c}\text { Poisson's } \\
\text { ratio }\end{array}$} & $\begin{array}{c}\text { Density } \\
\left(\mathrm{kg} / \mathrm{m}^{3}\right)\end{array}$ \\
$E_{1}$ & $E_{2}$ & $E_{3}$ & $G_{12}$ & $G_{13}$ & $G_{23}$ & $\mu_{12}$ & $\mu_{13}$ & $\mu_{23}$ & $\rho$ \\
\hline 8.817 & 925 & 548 & 805 & 584 & 183 & 0.21 & 0.45 & 0.43 & 1220 \\
\hline
\end{tabular}

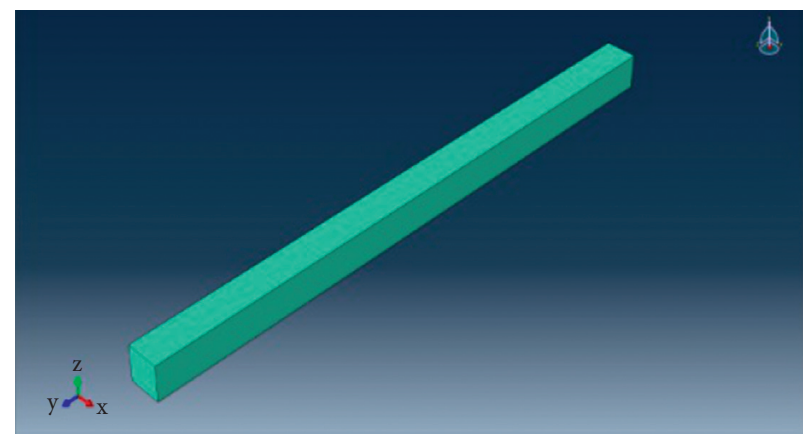

FIgURE 1: The finite-element model of glue-laminated cornstalk scrimber under axial compression.

cloud atlas of buckling equivalent stresses and buckling equivalent displacements of Z-1 to Z-5 were obtained (Figures 2 and 3).

As shown in Figures 2 and 3, the buckling equivalent stress mainly concentrated in the middle of the specimens under axial compression. When the sectional area was fixed, Z-5 had the greatest deflection under ultimate load, while Z-1 had the smallest deflection. The deflection of the axial compression specimen gradually increased with the growth in specimen height. From Z-1 to Z-5, the eigenvalue buckling load was $605 \mathrm{kN}, 545 \mathrm{kN}, 526 \mathrm{kN}, 502 \mathrm{kN}$, and $456 \mathrm{kN}$, respectively.

2.4.2. Nonlinear Buckling Analysis. The five axial compression specimens were subject to nonlinear analysis. In this way, the nonlinear buckling load of Z-1 to Z-5 was obtained as $564 \mathrm{kN}, 523 \mathrm{kN}, 504 \mathrm{KN}, 465 \mathrm{kN}$, and $425 \mathrm{kN}$, respectively. As shown in Figure 4, the nonlinear buckling load was slightly smaller than the eigenvalue buckling load; the two loads exhibited roughly the same trend: the greater the slenderness ratio, the smaller the load and the weaker the resistance to lateral displacement.

As shown in Figures 5 and 6, for Z-1 to Z-5, the transverse displacement and axial displacements changed similarly under compression load: both of them gradually increased with the load and with the slenderness ratio. In other words, the bearing capacity decreased with the growing load and slenderness ratio. In the early phase of loading, transverse displacement and axial displacements increased almost linearly; the transverse displacement had the greater increasing rate. Later, as the load continued to grow, the traverse displacement tended to be stable, while the axial displacement still exhibited a linear growth. 
TABLe 2: The model size.

\begin{tabular}{lccc}
\hline Specimen number & Sectional area $\left(\mathrm{mm}^{2}\right)$ & Length $(\mathrm{mm})$ & Slenderness ratio \\
\hline Z-1 & & 1200 & 27.7 \\
Z-2 & $150 \times 150$ & 1600 & 37.0 \\
Z-3 & & 2000 & 46.2 \\
Z-4 & & 2400 & 54.2 \\
Z-5 & 2800 & 63.2 \\
\hline
\end{tabular}

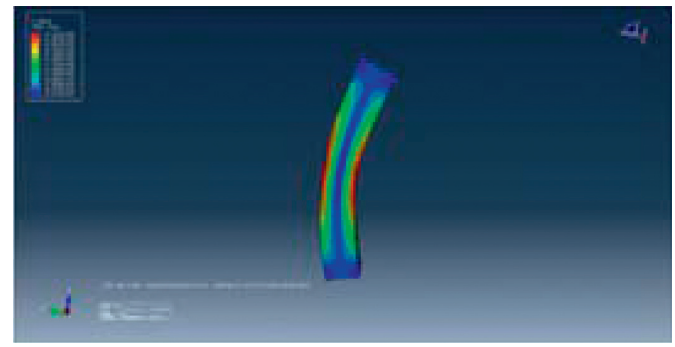

(a)

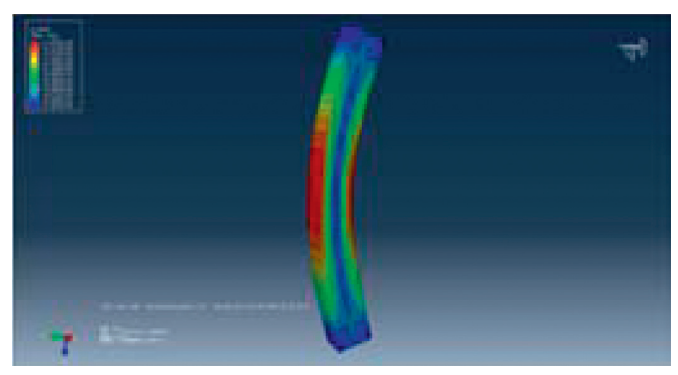

(c)

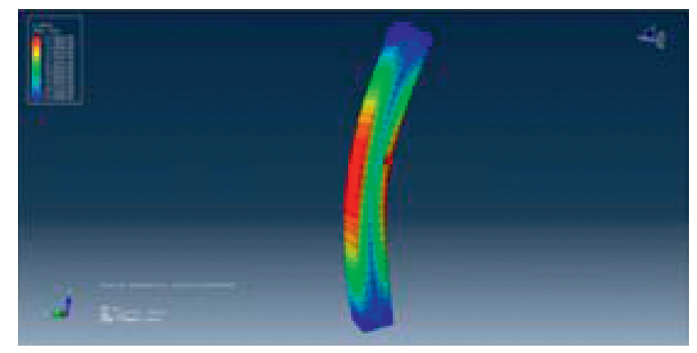

(b)

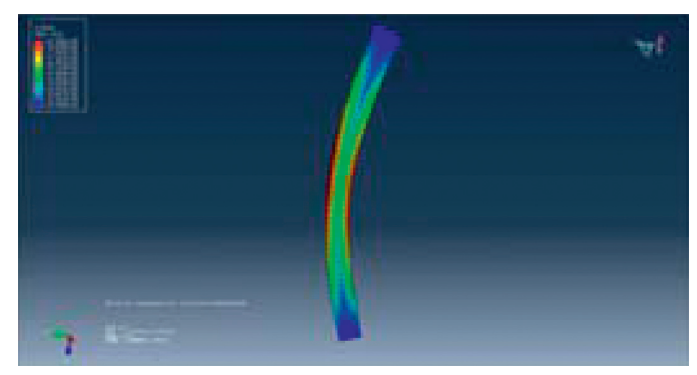

(d)

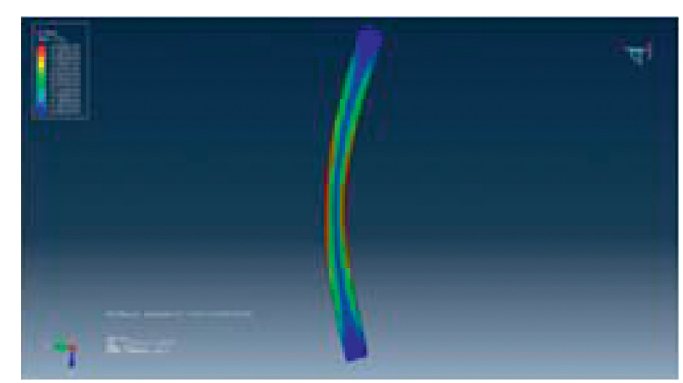

(e)

Figure 2: The cloud atlas of buckling equivalent stresses.

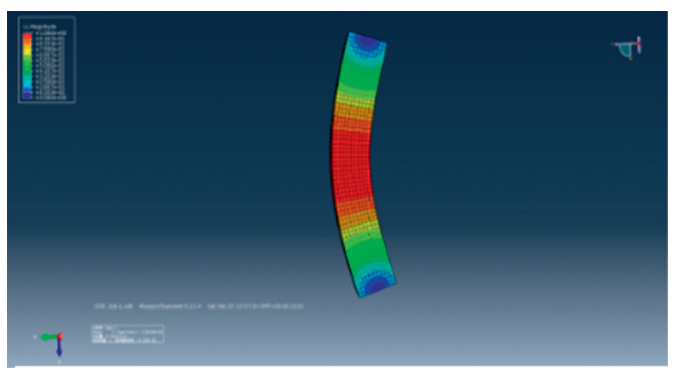

(a)

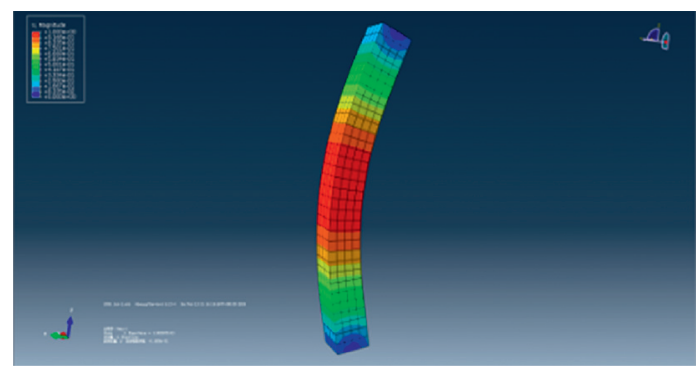

(b)

Figure 3: Continued. 


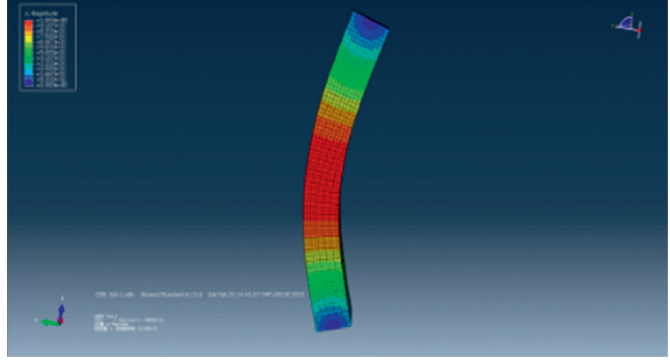

(c)

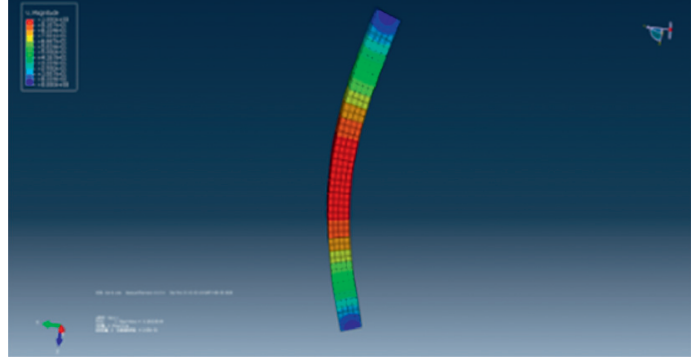

(d)

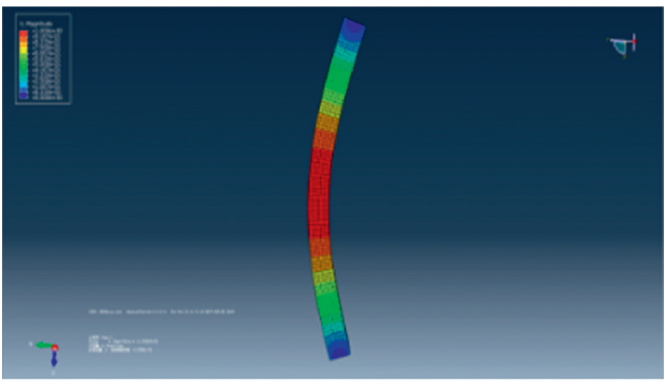

(e)

Figure 3: The cloud atlas of buckling equivalent displacements.

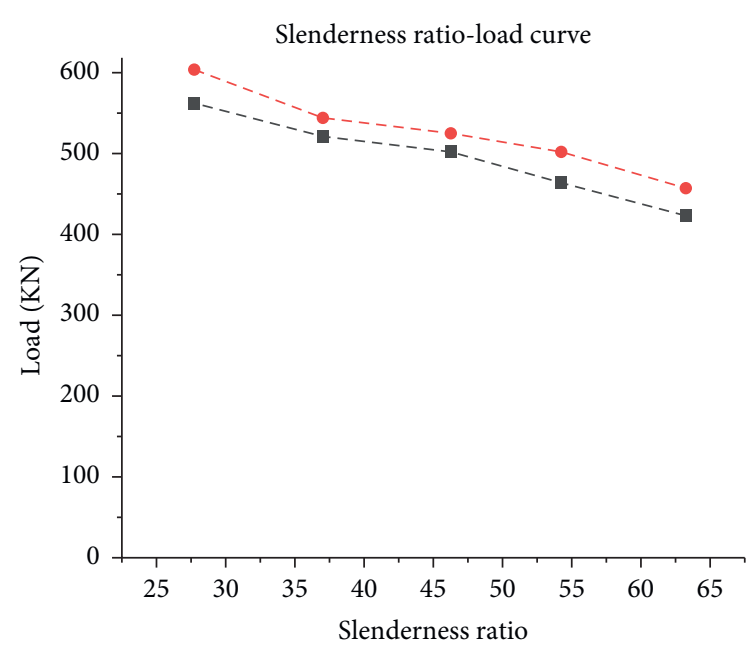

- - Nonlinear buckling load

- - Eigenvalue buckling load

Figure 4: The slenderness ratio-load curves.

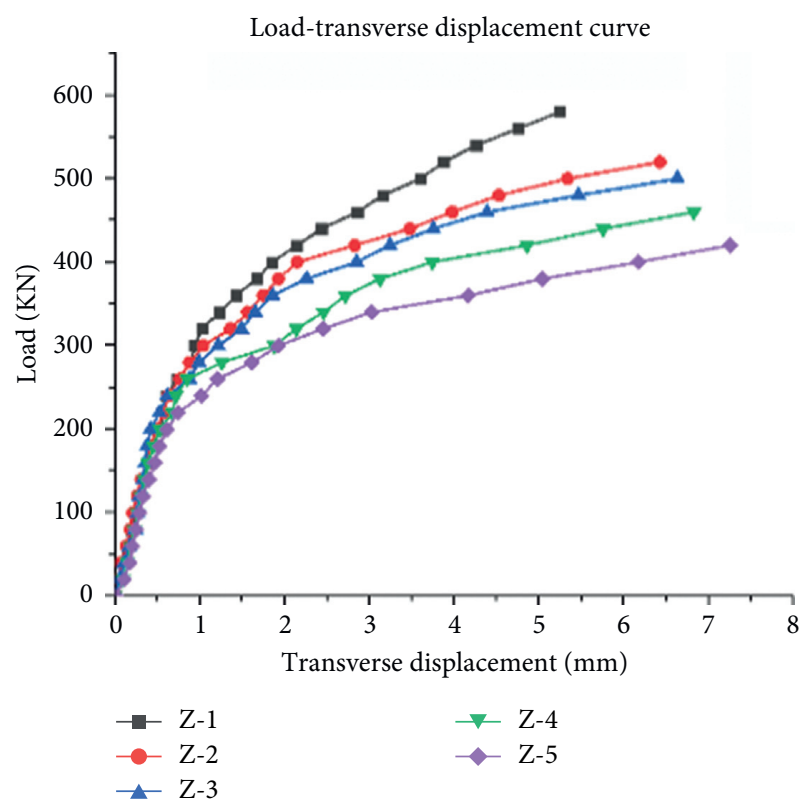

FIgURE 5: The load-transverse displacement curves. 


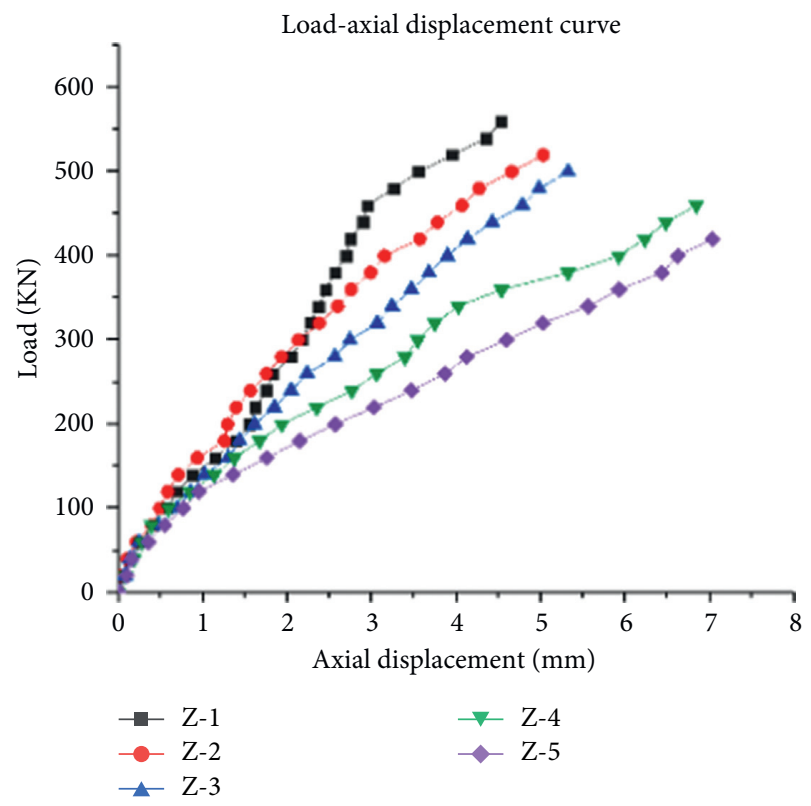

Figure 6: The load-axial displacement curves.

\section{Conclusions}

This paper carries out Abaqus finite-element simulation of glue-laminated cornstalk scrimber specimens with different slenderness ratios under axial compression. The generalized Hill yield criterion was introduced for elastoplastic analysis, in view of the nonlinear property of the material; through eigenvalue and nonlinear buckling analyzes, the cloud atlas of buckling equivalent stress and displacement and nonlinear load-displacement curves were obtained. The main conclusions are as follows:

(1) With the growing slenderness ratio, both eigenvalue buckling load and nonlinear buckling load gradually decreased, and the former was slightly greater than the latter. The eigenvalue buckling analysis assumes that the specimens are ideal elastic members, while the nonlinear buckling analysis considers the initial defects of the members. Therefore, the nonlinear buckling analysis better conforms to the actual situation and outputs more reliable results.

(2) According to the nonlinear buckling load-displacement curves, both transverse displacement and longitudinal displacements gradually increased with slenderness ratio. In the early phase of loading, transverse displacement and axial displacements increased almost linearly; the transverse displacement had the greater increasing rate. With further growth of the load, the traverse displacement tended to be stable, while the axial displacement continued to increase linearly at the original rate.

(3) The buckling load and nonlinear load of the axial compression specimens gradually decreased with the growth in specimen height. Moreover, the transverse displacement and axial displacements changed similarly under axial compression: both of them gradually increased with the height of specimen.

\section{Data Availability}

The data used to support the findings of this study are available from the corresponding author upon request.

\section{Conflicts of Interest}

The authors declare that they have no conflicts of interest.

\section{Acknowledgments}

This work was financially supported by the Major Science and Technology Project Foundation of Jilin Province in China (20180201066SF).

\section{References}

[1] G. B. Hu, Z. T. Zhang, and X. B. Xiao, "China import wood situation and developing trend," Forest Industry, vol. 42, no. 1, pp. 5-9, 2015.

[2] X. Sun, M. He, and Z. Li, "Novel engineered wood and bamboo composites for structural applications: state-of-art of manufacturing technology and mechanical performance evaluation," Construction and Building Materials, vol. 249, Article ID 118751, 2020.

[3] M. Uzel, A. Togay, Ö. Anil, and C. Sogutlu, "Experimental investigation of flexural behavior of glulam beams reinforced with different bonding surface materials," Construction and Building Materials, vol. 158, pp. 149-163, 2018.

[4] A. D'Aveni and G. D'Agata, "Post-tensioned timber structures: new perspectives," Construction and Building Materials, vol. 153, pp. 216-224, 2017.

[5] R. Brandner, "Cross laminated timber (CLT) in compression perpendicular to plane: testing, properties, design and recommendations for harmonizing design provisions for structural timber products," Engineering Structures, vol. 171, pp. 944-960, 2018.

[6] G. Kandler, M. Lukacevic, C. Zechmeister, S. Wolff, and J. Füssl, "Stochastic engineering framework for timber structural elements and its application to glued laminated timber beams," Construction and Building Materials, vol. 190, pp. 573-592, 2018.

[7] B. Anshari and Z. Guan, "FE modelling of optimization on strengthening glulam timber beams by using compressed wood blocks," Procedia Engineering, vol. 171, pp. 857-864, 2017.

[8] D. S. Huang, A. P. Zhou, and Y. L. Bian, "Experimental and analytical study on the nonlinear bending of parallel strand bamboo beams," Construction and Building Materials, vol. 44, pp. 585-592, 2013.

[9] A. K. Ray, S. Mondal, S. K. Das, and P. Ramachandrarao, "Bamboo-A functionally graded composite-correlation between microstructure and mechanical strength," Journal of Materials Science, vol. 40, no. 19, pp. 5249-5253, 2005.

[10] M. H. Ge, Research on Current Situation and Comprehensive Utilization of Straw Resources in Jilin Province, Master thesis of Northeast Normal University, 2011.

[11] H. Liu, L. M. Zhang, and N. Q. Wang, "Research on current situation and development of straw panel," China New Technologies and New Products, vol. 2014, no. 5, p. 131, 2014. 
[12] G. H. Chen, "Study on surface properties and gluing recombination technology of crop straw," Master thesis, of Central South University of Forestry and Technology, Changshu, China, 2006.

[13] C. Martins, A. M. P. G. Dias, and H. Cruz, "Bonding performance of Portuguese Maritime pine glued laminated timber," Construction and Building Materials, vol. 223, pp. 520-529, 2019.

[14] X. Li, Z. Cai, and J. Z. Winandy, "Effect of oxalic acid and steam pretreatment on the primary properties of UF-bonded rice straw particleboards," Industrial Crops and Products, vol. 33, no. 3, p. 665 669, 2012.

[15] J. A. Newlin and J. M. Gahagan, "Tests of large timber columns and presentation of the forest products laboratory column formula," United States Department of Agriculture, Washington. D.C, USA, Technical Bulletin No.167, 1930.

[16] B. Sharma and K. A. Harries, "Effect of fiber gradation on the edge bearing strength of bamboo culms," Key Engineering Materials, vol. 517, pp. 63-70, 2012.

[17] T. Reynolds, B. Sharma, K. Harries, and M. Ramage, "Dowelled structural connections in laminated bamboo and timber," Composites Part B: Engineering, vol. 90, pp. 232-240, 2016.

[18] J. J. Zahn and D. R. Rammer, "Design of glued laminated timber columns," Journal of Structural Engineering, vol. 121, no. 12, pp. 1789-1794, 1995.

[19] Z. Li, M. He, D. Tao, and M. Li, "Experimental buckling performance of scrimber composite columns under axial compression," Composites Part B: Engineering, vol. 86, pp. 203-213, 2016.

[20] P. Luna, C. Takeuchi, C. Alvarado, and I. Moreno, "Glued laminated Guadua angustifolia bamboo columns," in I International Symposium on Genetic Resources of Bamboos and Palms and III International Symposium on Ornamental Palmsvol. 1003, pp. 125-130, 2013.

[21] H.-t. Li, J.-W. Su, Q.-S. Zhang, A. J. Deeks, and D. Hui, "Mechanical performance of laminated bamboo column under axial compression," Composites Part B: Engineering, vol. 79, pp. 374-382, 2015. 